\title{
Development of an Insect Herbivore and its Pupal Parasitoid Reflect Differences in Direct Plant Defense
}

\author{
Jeffrey A. Harvey • Rieta Gols • Roel Wagenaar • \\ T. Martijn Bezemer
}

Received: 12 December 2006 / Revised: 12 March 2007 / Accepted: 9 April 2007 /

Published online: 21 June 2007

(C) Springer Science + Business Media, LLC 2007

\begin{abstract}
In nature, plants defend themselves by production of allelochemicals that are toxic to herbivores. There may be considerable genetic variation in the expression of chemical defenses because of various selection pressures. In this study, we examined the development of the small cabbage butterfly, Pieris rapae, and its gregarious pupal ectoparasitoid, Pteromalus puparum, when reared on three wild populations (Kimmeridge, Old Harry, Winspit) of cabbage, Brassica oleracea, and a Brussels sprout cultivar. Wild plant populations were obtained from seeds of plants that grow naturally along the south coast of Dorset, England. Significant differences in concentrations of allelochemicals (glucosinolates) were found in leaves of plants damaged by P. rapae. Total glucosinolate concentrations in Winspit plants, the population with the highest total glucosinolate concentration, were approximately four times higher than in the cultivar, the strain with the lowest total glucosinolate concentration. Pupal mass of $P$. rapae and adult body mass of Pt. puparum were highest when reared on the cultivar and lowest when developing on Kimmeridge plants, the wild strain with the lowest total glucosinolate concentration. Development of male parasitoids was also more negatively affected than female parasitoids. Our results reveal that plant quality, at least for the development of 'adapted' oligophagous herbivores, such as $P$. rapae, is not based on total glucosinolate content. The only glucosinolate compound that corresponded with the performance of $P$. rapae was the indole glucosinolate, neoglucobrassicin. Our results show that performance of ectoparasitoids may closely reflect constraints on the development of the host.
\end{abstract}

\footnotetext{
J. A. Harvey $(\bowtie) \cdot$ R. Wagenaar $\cdot$ T. M. Bezemer

Department of Multitrophic Interactions, Netherlands Institute of Ecology, P.O. Box 40, 6666 Heteren, The Netherlands e-mail: J.harvey@nioo.knaw.nl
}

R. Gols • T. M. Bezemer

Laboratory of Entomology, Wageningen University, P.O. Box 8031, 6700 Wageningen, The Netherlands

T. M. Bezemer

Laboratory of Nematology, Wageningen University, P.O. Box 8123, 6700 Wageningen, The Netherlands 
Keywords Allelochemical Brassica oleracea $\cdot$ Glucosinolates Pieris rapae Pteromalus puparum $\cdot$ Parasitism

\section{Introduction}

Plants have evolved defenses against herbivores that use a wide array of direct mechanisms (Karban and Baldwin 1997). Direct defense mechanisms include morphological adaptations that impede herbivore colonization and movement on the plant, such as hairs, waxy leaf surfaces, or sticky secretions (van Dam and Hare 1998; Muller and Riederer 2005). Most plants also produce secondary metabolites that affect herbivore behavior and development. Allelochemicals may function as feeding deterrents for generalist herbivores (Akhtar and Isman 2004) or exhibit toxic effects on the development and physiology of herbivores by reducing their rates of growth and increasing mortality (Giamoustaris and Mithen 1995; Wold and Marquis 1997; van Dam et al. 2000). On the other hand, many herbivores have evolved specific metabolic adaptations that enable them to detoxify or excrete allelochemicals and their breakdown products (Ratzka et al. 2002; Wittstock et al. 2004). Still other species utilize plant allelochemicals as feeding and/or oviposition stimulants (Carter and Feeny 1999; Renwick and Lopez 1999) or sequester them as a putative defense against predators and parasitoids (Hunter 2000; Muller et al. 2001).

Several studies have found that there is considerable genetic variation in the expression of secondary plant metabolites, even in populations that are located in close proximity to each other (Fox 1981; Moyes et al. 2000; Agrawal 2005). This variation is thought to represent an adaptive response to a suite of selection pressures that may vary even over limited spatial and/or temporal gradients (Moyes et al. 2000). Biotic selection pressures, such as attack from herbivores and pathogens, and abiotic selection pressures, such as exposure to wind or access to water and nutrients, may play an important role in shaping the evolution of direct defenses in plants (Agrawal 2005). Competition with other plants may also be an important factor resulting in a trade-off between growth and defense (van Dam et al. 2000).

Most researchers now agree that natural enemies of arthropod herbivores, such as parasitoids and predators, must also be considered in models examining the evolution of direct defense strategies in plants (Price et al. 1980). This approach has generally argued that natural enemies, by regulating herbivore populations, can act as important selective agents by reducing the need for plants to invest in chemical defenses when these are costly to maintain (van Dam et al. 2000; Ode et al. 2004). However, one of the major problems with this argument is that it assumes that the development of natural enemies is independent of plant quality, thus ignoring that natural enemies obtain their nutrition indirectly from the plant through the herbivore. A number of studies have reported that allelochemicals in the diet of hosts or prey negatively affect the development of their parasitoids and predators (Barbosa et al. 1986, Duffey et al. 1986; Gunasena et al. 1990; Traugott and Stamp 1996; Havill and Raffa 2000; reviewed by Harvey 2005 and Ode 2006). Further, the effects of allelochemicals may even be manifested in the fourth trophic level (Orr and Boethel 1986; Harvey et al. 2003; Soler et al. 2005), showing that they can work their way up through the food chain.

In this study, we compared the development of the small cabbage white butterfly, Pieris rapae L. (Lepidoptera: Pieridae), and its gregarious ectoparasitoid, Pteromalus puparum L. (Hymenoptera: Pteromalidae) when the herbivore was reared on three wild populations and one cultivar of cabbage, Brassica oleracea L. (Capparales: Brassicaceae). Previous work found that there were significant differences in the expression of glucosinolates in wild 
cabbage plants among the different Dorset populations (Mithen et al. 1995; Moyes et al. 2000). Domestication in B. oleracea has also resulted in a significant reduction of foliar levels of glucosinolates (Benrey et al. 1998). We included a cabbage cultivar with low levels of glucosinolates compared to the wild Dorset populations. Pieris rapae is a specialist herbivore that feeds exclusively on plants producing glucosinolates (Mithen et al. 1995; Renwick and Lopez 1999). Glucosinolates and their breakdown products act as feeding deterrents or exhibit detrimental effects on the growth and development of herbivores, pathogens, and nematodes (Potter et al. 1999; Li et al. 2000; Buskov et al. 2002). On the other hand, they are also known to act as oviposition and feeding stimulants for specialist herbivores such as Pieris rapae (van Loon and Schoonhoven 1999; Renwick and Lopez 1999).

We compared pupal weight of Pieris rapae caterpillars that were reared in the laboratory on the three wild strains and cultivar of B. oleracea. We then examined adult wasp body mass and development time in Pteromalus puparum when reared from pupae of Pieris rapae. Finally, we measured levels of glucosinolates in foliage of $B$. oleracea. The main aim of the experiment was to determine if there are differences in plant quality among the different strains of $B$. oleracea, based on foliar levels of glucosinolates, and if these are reflected in patterns of herbivore and parasitoid development.

\section{Methods and Materials}

Plants Seeds of B. oleracea were collected from three populations growing on or close to chalk cliffs along the south coast of Great Britain, near Swanage, Dorset. Two of the populations (Winspit, Kimmeridge) are located less than $5 \mathrm{~km}$ from each another; the third (Old Harry) occurs approximately $10 \mathrm{~km}$ east of the Winspit population. The coordinates for each of the populations are: Old Harry $\left(50^{\circ} 38^{\prime} \mathrm{N}, 1^{\circ} 55^{\prime} \mathrm{E}\right)$, Kimmeridge $\left(50^{\circ} 35^{\prime} \mathrm{N}, 2^{\circ} 03^{\prime} \mathrm{E}\right)$, and Winspit $\left(50^{\circ} 34^{\prime} \mathrm{N}, 2^{\circ} 02^{\prime} \mathrm{E}\right)$. In addition, a cultivated strain of B. oleracea (Brussels sprout) cv. Cyrus was included.

Seeds from the different strains were germinated in the first week of October, 2005. Seedlings were transferred to $2.1-1$ pots filled with potting soil consisting of approximately $30 \%$ sand, $5 \%$ clay, and $65 \%$ peat. Plants were grown at The Netherlands Institute of Ecology, Heteren, in a greenhouse at $22 \pm 2{ }^{\circ} \mathrm{C}, 40-80 \% \mathrm{RH}$, with a photoperiod of at least $16 \mathrm{hr}$. If the light dropped below $500 \mu \mathrm{mol}$ photons $\mathrm{m}^{-2} \mathrm{sec}^{-1}$ during the $16 \mathrm{hr}$ photoperiod, supplementary illumination was supplied by high-pressure mercury lamps. Plants were watered daily. Starting when 4-wk old, the plants were fertilized once a week with 0.5 regular Hoagland solution, which was applied to the soil. All B. oleracea plants were 7-wk old when they were used in experiments.

Insects Pieris rapae feeds exclusively on plants in the Order Capparales that produce glucosinolates, and especially on species of the Brassicaceae, and is considered to be a major pest in cabbage crops in many parts of the world. During its development, Pieris rapae passes through five instars before pupating on leaves or stems of the plant. Pteromalus puparum is known to attack pupae in several families of butterflies, including species of the Nympahlidae and Pieridae (Lei et al. 1997; Barron et al. 2004; Wold-Burkness et al. 2005). It is considered to be an important biological control agent of Pieris rapae (Lee and Heimpel 2005). The parasitoid must first host-feed before initiating oogenesis. Host feeding occurs when the female parasitoid creates a wound in the host cuticle by repeatedly inserting and removing her ovipositor over the course of several minutes. After this time, haemolymph begins oozing 
through the wound and is consumed by the parasitoid. Eggs usually are produced within $48 \mathrm{hr}$ of a host-feeding bout.

All insects used in the experiments originated from cabbage fields in the vicinity of Wageningen. Cultures of all herbivores were maintained in the laboratory on Brussels sprouts cv. Cyrus for many years and reared in climate rooms at $22 \pm 2{ }^{\circ} \mathrm{C}, 40-80 \%$ r.h, and a light regime of L16:D8. Pteromalus puparum were obtained from pupae of Pieris rapae and the closely related large cabbage white butterfly $P$. brassicae in June, 2005 and were thereafter reared on pupae of $P$. brassicae. Parasitized butterfly pupae were maintained in large Petri dishes (20-cm diameter) and were monitored until adult parasitoid emergence. Emerged adult wasps were then placed in separate Petri dishes and were provided with water and honey ad libitum. For parasitism, we used females that were 5- to 10-d old after adult emergence.

Development of Pieris rapae and Pteromalus puparum on B. oleracea To compare the effects of plant quality on herbivore and parasitoid development, Pieris rapae and Pteromalus puparum were reared on three wild strains and one cultivar of B. oleracea. To obtain eggs of Pieris rapae, one plant from each strain was placed in an insect-rearing cage containing at least 50 adult butterflies for $4 \mathrm{hr}$. After this period, plants were removed from the cages and placed in a rearing room until the eggs hatched. When the larvae reached the second instar (=L2), they were transferred to new plants with a distribution of nine larvae per plant. A total of six plants were used to rear 54 Pieris rapae per strain. During their development, caterpillars were allowed to develop and move around freely on the plants until they reached the final instar. When larvae had developed into late fifth instar, they were transferred to plastic containers $(15 \times 10 \times 10 \mathrm{~cm})$ with some leaf material from the plants they were previously feeding on. After pupation, the pupae were carefully collected and weighed on a Cahn C-29 microbalance (Cahn Instruments, Cerritos, CA, USA; accuracy, $\pm 1 \mu \mathrm{g}$ ). A subset of these weighed pupae was used for parasitism by the parasitoid, Pteromalus puparum (see below). In addition to pupal mass, egg-to-pupa development time and survival (egg-to-pupa) were recorded when reared on the different plant strains. Plants with insects were maintained in a greenhouse compartment under the same conditions as described in "Plant" section.

A subset of 15 pupae reared from each strain of $B$. oleracea was selected to be parasitized by Pteromalus puparum, ensuring that there were no significant differences in mean pupal fresh mass (Table 2). This avoided the potential problem of disentangling the effects of pupal mass and plant strain on parasitoid development. Individual, mated parasitoid females that had previously been host-fed were provided with single pupae of Pieris rapae originating from one of the four B. oleracea strains in large Petri dishes for $24 \mathrm{hr}$ (thus, the number of female parasitoids used was the same as for the number of pupae in Table2). After this time, the female wasps were removed, and the parasitized butterfly pupae were monitored several times daily until adult parasitoid emergence. Newly emerged wasps were sexed, killed by freezing, and then placed in a preheated oven at $70^{\circ} \mathrm{C}$ for $3 \mathrm{~d}$ to obtain dry-mass data. All wasps within broods were then weighed on the Cahn balance. Development times were recorded as the number of days between the termination of the initial 24-hr parasitism period and adult eclosion. Unfortunately, some parasitoids failed to parasitize Pieris rapae pupae (i.e., adult butterflies enclosed), and these were eliminated from analyses. The sample size (hosts parasitized) was therefore: Cyrus=12, Kimmeridge $=7$, Old Harry=14, and Winspit $=7$.

Glucosinolate Analyses As an indicator of direct plant defense, we measured glucosinolate concentrations in leaf tissues of $B$. oleracea from the different strains. All plants that were used for insect development, six plants per plant strain, were also sampled for glucosinolate analysis. When leaf samples were taken, the damaged plant groups had been exposed to 
Pieris rapae feeding for $7 \mathrm{~d}$. Two discs, 7-mm diameter, were punched per leaf, one from each central part of a leaf half, and six fully unfolded leaves were sampled per plant. Leaf discs were pooled per plant in 2-ml Eppendorf vials and frozen in liquid nitrogen immediately after sampling and stored at $-80^{\circ} \mathrm{C}$. Samples were later freeze-dried and pulverized. Fifty-milligram aliquots of freeze-dried material were weighed in 2-ml centrifuge tubes. Glucosinolates were extracted and purified as described by van Dam et al. (2004). Glucosinolates were separated on a reverse phase C-18 column (Alltima C-18, $3 \mu \mathrm{m}, 150 \times 4.6 \mathrm{~mm}$, Alltech,Deerfield, IL, USA) on high performance liquid chromatography (HPLC; Dionex, Sunnyvale, CA, USA) with an acetonitrile-water-gradient. Detection was performed with a Dionex PDA-100 photodiode array detector set to scan from 200 to $350 \mathrm{~nm}$. For quantification, sinigrin (Sigma, St. Louis, MO, USA) was used as an external standard. Peaks were integrated at $229 \mathrm{~nm}$ for which standard response factors have been defined. Leaf tissues of $B$. oleracea contain aliphatic and indole glucosinolates. The aliphatic glucosinolates have a side chain length derived from a propyl (C3) or butyl (C4) group. These different glucosinolates (indoles, C3, C4) were identified based on their retention times and UV spectra compared to those of pure compounds (sinigrin, Sigma, St, Louis, MO., USA), glucotropaeolin, glucobrassicin (kindly provided by M. Reichelt, MPI for Chemical Ecology, Jena, Germany), or compared to a certified oil seed reference (EC Community Bureau of Reference BCR-367R, Fluka, Buchs, Switzerland). For a more detailed description of the method, see van Dam et al. (2004).

Statistical Analyses Survival of Pieris rapae was analyzed by using a chi-square test. Data on development time and pupal mass of Pieris rapae, brood size of Pteromalus puparum, and glucosinolate content in the different $B$. oleracea strains were analyzed by analysis of variance (ANOVA) with plant strain as factor. Normality and homogeneity of variance were checked by inspection of the residuals after model fitting and transformed if necessary. Brood size was square-root transformed; glucosinolate contents were log-transformed. The TukeyKramer method was used for multiple comparisons of means. For Pteromalus puparum development time and adult weight, multiple datapoints were associated to each host pupa. Therefore, these data were analyzed with a mixed model (REML) in Genstat 7. The analysis calculates Wald-type $F$-statistics and can process different sources of variation, enabling the use of all individuals rather than using averages per host (Piepho et al. 2003). Data were analyzed with strain, sex (male or female), and the interaction as fixed factors and host pupa as random factor. Predicted means and standard errors and individual comparisons estimated after model fitting were used for presentation of the results.

\section{Results}

Glucosinolate Profiles Total glucosinolate levels were higher in the wild populations than in the cultivar (Fig. 1). The rank order of total glucosinolates levels in the different populations is: Cultivar $<$ Kimmeridge $<$ Old Harry $<$ Winspit. Glucosinolate concentrations of individual compounds differed significantly among the populations, except for glucoraphanin, progoitrin, and 4-hydroxy glucobrassicin (Table 1). In Winspit and Old Harry plants, the aliphatic glucosinolate with the highest concentration was gluconapin, although levels of gluconapin were significantly higher in Winspit than in Old Harry plants. In the cultivar, glucoiberin dominated the aliphatic glucosinolate profile. In contrast, Kimmeridge plants contained low levels of aliphatic glucosinolates $(<2 \mu \mathrm{g} / \mathrm{g}$ DW all aliphatic glucosinolates combined). The wild populations contained significantly higher levels of the indole 
Fig. 1 Mean total glucosinolate concentrations $(N=6)$ in foliage of one cultivar $(C Y R)$ and three wild populations of $B$. oleracea (KIM, OH and WINS) after $7 \mathrm{~d}$ of feeding by Pieris rapae. Total glucosinolates are divided into propyl (C3) derived aliphatic, butyl (C4) derived aliphatic, and indole glucosinolates

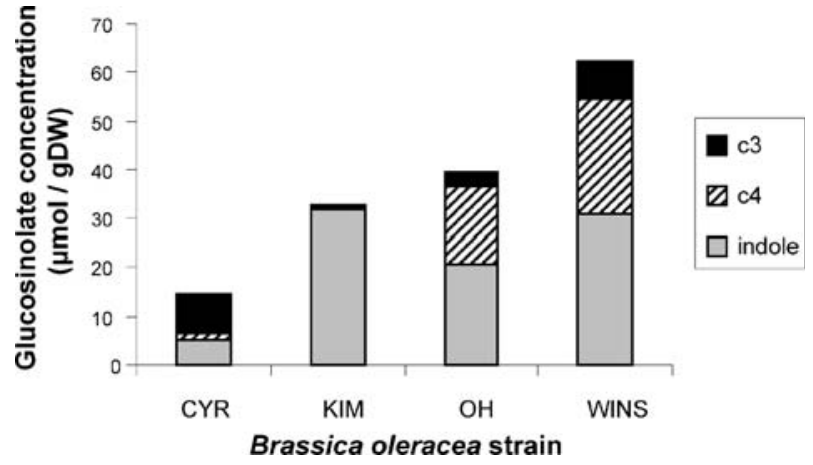

glucosinolate glucobrassicin than the cultivar. Furthermore, the Kimmeridge and Winspit plants contained higher amounts of neoglucobrassicin than the other two populations.

Development of Unparasitized Pieris rapae on Different Strains of Brassica oleracea Survival of Pieris rapae varied with plant strain in $B$. oleracea $\left(\chi_{3}^{2}=9.69, P=0.021\right)$. Herbivore survival to pupation was almost $90 \%$ or higher in all strains with the exception of Kimmeridge plants, where only $76 \%$ of caterpillars successfully pupated (Fig. 2a).

Pupal mass varied with plant strain in B. oleracea plants $\left(F_{3,186}=44.58, P<0.001\right.$; Fig. 2b). Pupae were largest when larvae of Pieris rapae were reared on the cultivar (Cyrus) and Old Harry plants and smallest when reared on Kimmeridge plants (Fig. 1). Plants from the Winspit population were of intermediate quality. Larval development time in Pieris rapae also varied with plant $\operatorname{strain}\left(F_{3,186}=4.99, P=0.002\right)$. Pieris rapae larvae took much longer to reach pupation on Kimmeridge plants than on Cyrus or Old Harry plants (Fig. 2c). Development time was also slightly prolonged on Winspit plants.

Table 1 Glucosinolate concentrations (mean \pm SE $\mu \mathrm{mol} / \mathrm{g}$ DW) in foliage of four different populations of Brassica oleracea damaged by Pieris rapae for $7 \mathrm{~d}$

\begin{tabular}{|c|c|c|c|c|c|c|}
\hline Populations & $\begin{array}{l}\text { Kimmeridge } \\
(N=6)\end{array}$ & $\begin{array}{l}\text { Old Harry } \\
(N=6)\end{array}$ & $\begin{array}{l}\text { Winspit } \\
(N=6)\end{array}$ & $\begin{array}{l}\text { Cultivar } \\
(N=6)\end{array}$ & ANOVA $F_{3,24}$ & $P$ Value \\
\hline \multicolumn{7}{|c|}{ C3 aliphatic glucosinolates } \\
\hline Glucoiberin & $0.22 \pm 0.14 \mathrm{a}$ & $1.32 \pm 0.83 \mathrm{a}$ & $0.44 \pm 0.44 \mathrm{a}$ & $6.25 \pm 0.55 b$ & 17.23 & $<0.001$ \\
\hline Sinigrin & $0.38 \pm 0.19 a$ & $1.63 \pm 0.77 \mathrm{ab}$ & $7.12 \pm 2.10 \mathrm{~b}$ & $1.92 \pm 0.41 \mathrm{ab}$ & 7.33 & 0.002 \\
\hline \multicolumn{7}{|c|}{$\mathrm{C} 4$ aliphatic glucosinolates } \\
\hline Glucoraphanin & $0.11 \pm 0.07 \mathrm{a}$ & $4.33 \pm 2.66 \mathrm{a}$ & $1.11 \pm 0.71 \mathrm{a}$ & $0.84 \pm 0.09 a$ & 2.18 & 0.12 \\
\hline Gluconapin & $0.00 \pm 0.00 \mathrm{a}$ & $8.63 \pm 3.27 b$ & $20.01 \pm 2.10 \mathrm{c}$ & $0.00 \pm 0.00 \mathrm{a}$ & 30.74 & $<0.001$ \\
\hline Progoitrin & $0.30 \pm 0.24 \mathrm{a}$ & $3.19 \pm 2.73 \mathrm{a}$ & $2.53 \pm 2.06 \mathrm{a}$ & $0.49 \pm 0.06 \mathrm{a}$ & 0.65 & 0.59 \\
\hline \multicolumn{7}{|l|}{ Indole glucosinolates } \\
\hline Glucobrassicin & $19.22 \pm 2.98 \mathrm{a}$ & $18.26 \pm 3.43 a$ & $19.35 \pm 6.18 \mathrm{ab}$ & $4.80 \pm 0.65 b$ & 4.77 & 0.01 \\
\hline Neoglucobrassicin & $12.11 \pm 5.26 \mathrm{~b}$ & $1.95 \pm 1.46 \mathrm{a}$ & $11.36 \pm 3.60 \mathrm{~b}$ & $0.00 \pm 0.00 \mathrm{a}$ & 8.71 & 0.007 \\
\hline 4-hydroxy GBC & $0.14 \pm 0.04 \mathrm{a}$ & $0.20 \pm 0.04 \mathrm{a}$ & $0.12 \pm 0.03 \mathrm{a}$ & $0.19 \pm 0.01 \mathrm{a}$ & 1.51 & 0.24 \\
\hline 4-methoxy GBC & $0.09 \pm 0.01 \mathrm{a}$ & $0.07 \pm 0.03 \mathrm{a}$ & $0.12 \pm 0.04 \mathrm{a}$ & $0.23 \pm 0.01 b$ & 6.63 & 0.003 \\
\hline
\end{tabular}

ANOVA was used on $\ln (x+1)$ transformed data to reveal differences between the populations. Different letters within a row denote significantly different means (Tukey-Kramer multiple comparisons, $P<0.05$ ).

$N$ Number of samples per population; $G B C$ glucobrassicin 
Fig. 2 Development of Pieris rapae reared on three wild populations and a cultivar of Brassica oleracea. a Percentage survival from egg to pupa; b Mean ( \pm SE) pupal mass (mg), and c mean $( \pm \mathrm{SE})$ development time from oviposition until pupation (d). Bars with the same letters are not significantly different (Tukey's tests, $P>0.05$ ). Sample sizes: Cyrus, $N=48$, Kimmeridge $N=41$, Old Harry $N=49$, Winspit $N=52$ a

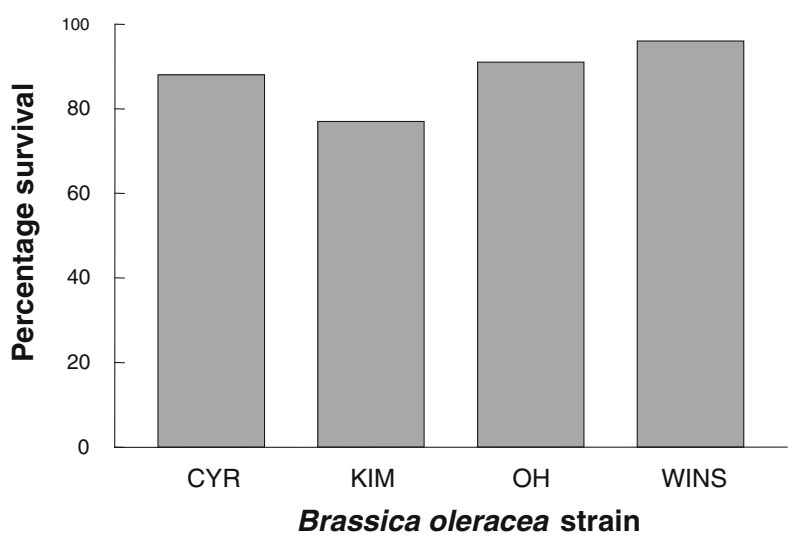

b

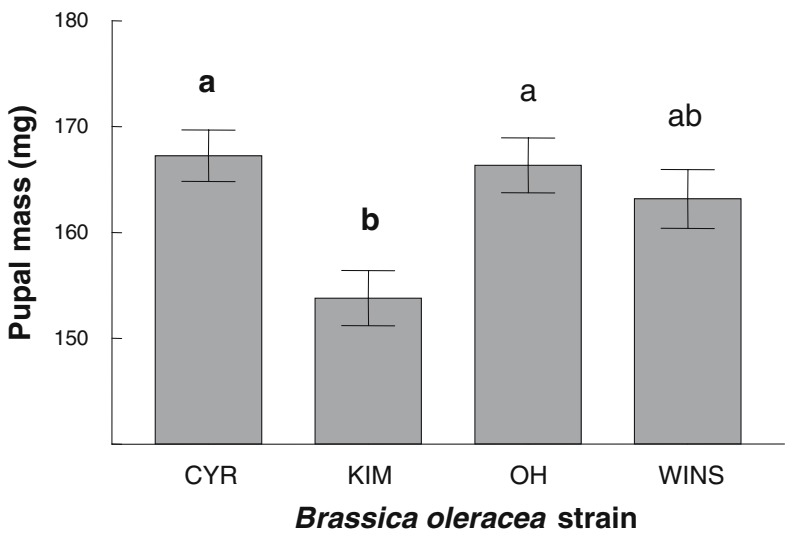

C

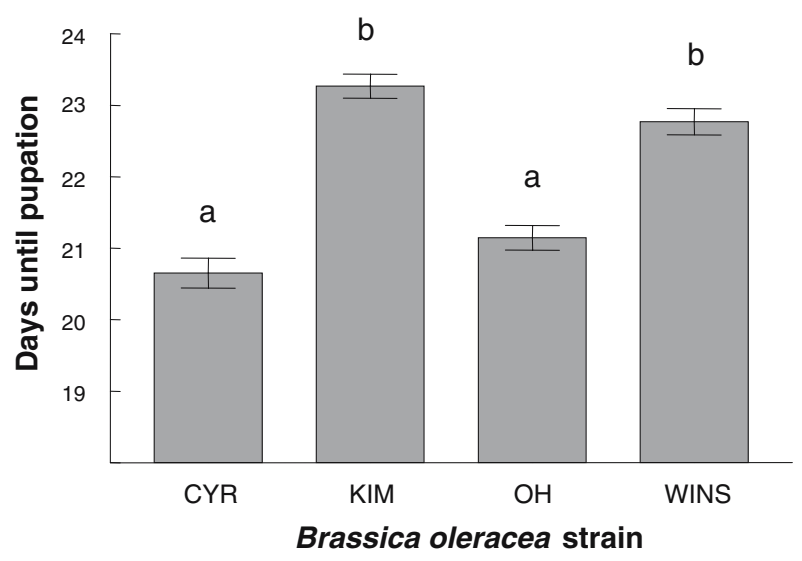


Table 2 Mean $( \pm \mathrm{SE})$ wet pupal masses $(\mathrm{mg})$ of Pieris rapae parasitized by Pteromalus puparum

\begin{tabular}{lcl}
\hline Plant Population & Sample Size & Mean Pupal Wet Mass (mg \pm SE) \\
\hline Cyrus & 12 & $165.97 \pm 3.13$ a \\
Kimmeridge & 7 & $161.67 \pm 8.00 \mathrm{a}$ \\
Old Harry & 14 & $162.83 \pm 4.65 \mathrm{a}$ \\
Winspit & 7 & $162.99 \pm 7.52 \mathrm{a}$ \\
\hline
\end{tabular}

Wet weights with the same letter are not significantly different $(P>0.05)$.

Pupal Mass of Pieris rapae Parasitized by Pteromlaus puparum Pupal mass of Pieris rapae selected for parasitism by Pteromalus puparum did not vary significantly across the different $B$. oleracea strains $\left(F_{3,36}=0.12, P=0.95\right.$; Table 2$)$. Irrespective of plant strain, the mean pupal mass of Pieris rapae that produced parasitoids was consistently between 160 and $165 \mathrm{mg}$ (Table 1$)$.

Primary Brood Size and Development of Pteromalus puparum on Pieris rapae pupae A total of 904 parasitoids emerged from 40 host pupae that had been reared on the four populations of $B$. oleracea. Brood size in Pteromalus puparum did not vary significantly when emerging from Pieris rapae pupae reared in the different strains of $B$. oleracea $\left(F_{1,36}=0.56, P=0.64\right.$; Fig. 3). Typical brood sizes were in the range of 20-26 wasps per host pupa (Fig. 3).

Body mass in Pteromalus puparum varied among strains of B. oleracea (Wald $=11.48$, $P=0.009$ ), but the interaction between strain and sex was also highly significant (Wald= $26.09, P<0.001)$. Overall, female wasps were larger than male wasps resulting in a significant difference between offspring sex (Wald=289.24, $P<0.001$ ). Parasitoid body mass varied among strains in male wasps (Wald $=14.02, P=0.003$; Fig. 4a) but not in female wasps (Wald $=4.76, P=0.19$; Fig. 4b). In male parasitoids, the largest wasps developed in Cyrus and Old Harry plants, whereas the smallest developed in plants from the Kimmeridge population. Winspit plants were of intermediate quality in this respect. Although there was no effect of plant strain in female wasps, the trend was similar to that observed in male wasps (Fig. 4a,b).

Egg-to-adult development time in Pteromalus puparum did not vary significantly among the different strains of $B$. oleracea (strain, Wald $=2.89, P=0.41$; strain $\times$ sex, Wald $=0.58 ; P=$ 0.90; Fig. 4c,d) but did vary with offspring sex (Wald=14.89, $P<0.001$ ). Pteromalus puparum is protandrous, with female wasps taking longer to complete their development than male wasps. Development in Pteromalus puparum takes about 3 wk to be completed.

Fig. 3 Mean $( \pm$ SE) brood size of Pteromlaus puparum emerging from pupae of Pieris rapae that were in turn reared on three wild populations and a cultivar of Brassica oleracea. Sample sizes (number of Pieris rapae pupae producing adult Pteromlaus puparum wasps from each plant population): Cyrus $N=12$, Kimmeridge $N=7$, Old Harry $N=14$, Winspit $N=7$

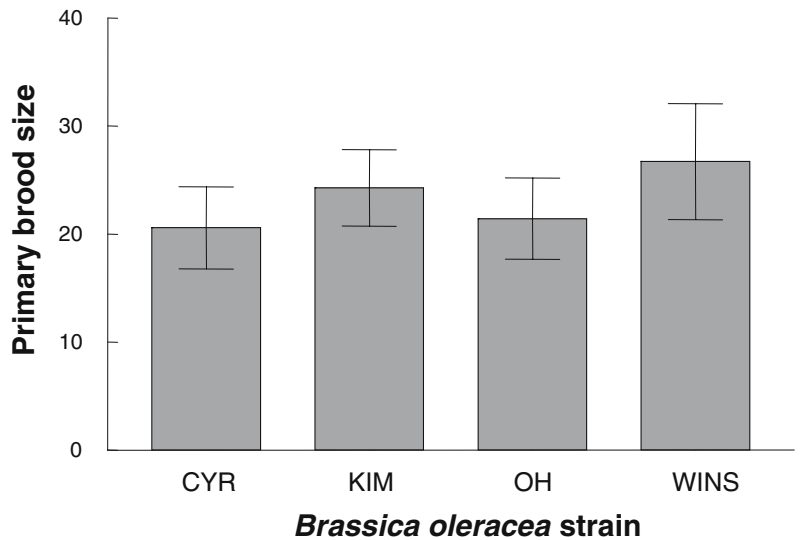


Fig. 4 Development of

Pteromlasus puparum emerging from pupae of Pieris rapae that were in turn reared on three wild populations and a cultivar of Brassica oleracea. Mean $( \pm \mathrm{SE})$ adult mass (mg), of

a males wasps and $\mathbf{b}$ female wasps; mean ( \pm SE) development time from oviposition until pupation (d) of c male wasps, and $\mathbf{d}$ female wasps. Means and standard errors are estimated after model fitting. Bars with the same letters are not significantly different (Tukey's tests, $P>0.05)$. Sample size as in Fig. 2
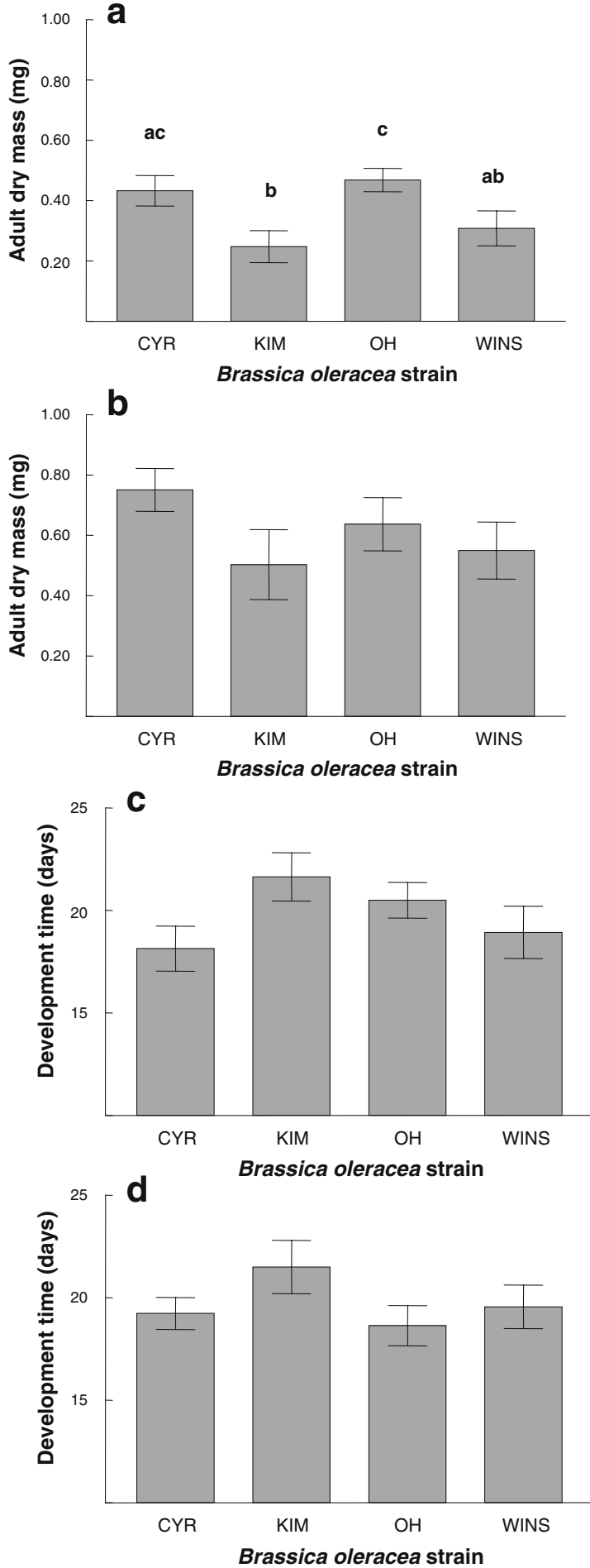


\section{Discussion}

We found that pupal mass of Pieris rapae and adult body mass of Pteromalus puparum varied nonlinearly with total glucosinolate levels in the four strains of $B$. oleracea. However, both the herbivore and its parasitoid appeared to be similarly affected by differences in plant quality. In both species, the largest individuals developed on the cultivar and Old Harry plants, whereas body mass was greatly reduced when developing on plants from the Kimmeridge population. Winspit plants were of intermediate quality. In Pieris rapae (but not Pteromalus puparum), development time also was extended for larvae reared on Kimmeridge plants. The similarity in the effect of plant strain on the body mass of Pieris rapae and Pteromalus puparum reveals that qualitative constraints on the herbivore were passed from the second to the third trophic level. Several other studies have reported variable effects of plant quality, probably mediated by allelochemicals, on the performance of insect parasitoids and predators (Campbell and Duffey 1979; Barbosa et al. 1986, Gunasena et al. 1990; Havill and Raffa 2000; Harvey et al. 2003, 2005, 2007).

If herbivore and parasitoid performance were positively correlated with total glucosinolate levels, we would have predicted that the rank order of plant quality would be cultivar $>$ Kimmeridge $>$ Old Harry $>$ Winspit. However, this was not the case, suggesting that total glucosinolate content does not determine plant quality for Pieris rapae. Glucosinolates and especially their hydrolysis products, (iso)thiocyanates, are known to be active against insect herbivory ( $\mathrm{Li}$ et al. 2000; Wittstock et al. 2004). However, Pieris rapae has developed an effective detoxification mechanism, which redirects the hydrolysis of glucosinolates into less toxic nitriles through the activity of a nitrile specifier protein (Wittstock et al. 2004). This glucosinolate detoxification system may render Pieris rapae relatively insensitive to high levels of glucosinolates.

The only glucosinolate compound that affected the performance of Pieris rapae was the indole glucosinolate, neoglucobrassicin. High concentrations of neoglucobrassicin in plants from the Kimmeridge and Winspit populations corresponded to reduced biomass and prolonged development of the herbivore when reared on these two populations. Indole glucosinolates are known to be induced by herbivory and fungal infection and to affect the growth and development of insect herbivores deleteriously (Rostás et al. 2002; Irwin et al. 2003). Levels of primary metabolites, such as nitrogen and amino acids, were not measured in this study. Although levels of these are unlikely to be limiting in cruciferous plants for herbivores (Soler et al. 2005), significantly different levels of nitrogen have been recorded in wild and cultivated species of crucifers (Slansky and Feeny 1977). In addition, levels of the enzyme myrosinase, which catalyzes the hydrolysis of glucosinolates, may also have varied in the different populations (Mithen 2001; Fahey et al. 2002).

In wild populations of $B$. oleracea growing along the south coast of England, previous work in the field also found that there was considerable variation in the expression of glucosinolates (Mithen et al. 1995; Moyes et al. 2000). However, although glucosinolates measured in plants from the same populations as those used in this study exhibited similar differences among populations (e.g., with Winspit plants containing the highest and Kimmeridge plants the lowest concentrations), overall total levels of glucosinolates in all three were higher than recorded here (Moyes et al. 2000).

The effect of plant quality on parasitoid size in Pteromalus puparum was more pronounced in male than in female wasps. For instance, adult male wasps emerging from Pieris rapae that had fed on Kimmeridge plants were almost $50 \%$ smaller, in terms of dry mass, than conspecifics emerging from hosts that had fed on the cultivar or Old Harry plants. By contrast, this difference in females, which was not significant statistically, was 
less than $25 \%$. This variation may be attributable to differing levels of selection in male and female wasps to achieve optimal body size. Although large size presumably benefits both sexes, large females are assumed to gain more in terms of fitness than males because egg production is more constrained in small females than sperm production is in small males (Charnov 1982).

As mentioned earlier, Wittstock et al. (2004) reported that Pieris rapae larvae do not sequester glucosinolates during feeding, but instead utilize a nitrile specifier protein in the gut to break them down into more harmless nitriles that are excreted with the feces. This suggests that internal host fluids and tissues should be less toxic for natural enemies that attack insects such as Pieris rapae than is the case with hosts or prey that actively sequester plant toxins into their own body tissues (Hunter 2000). However, other studies with herbivores that detoxify or excrete harmful plant allelochemicals have shown that the development of parasitoids may still be correlated negatively with levels of allelochemicals in host diet (Campbell and Duffey 1979; Barbosa et al. 1986, Harvey et al. 2007). In some parasitoids, trace amounts of secondary plant metabolites have also been found in their by-products, including cocoon silk and/or the meconium (Barbosa et al. 1986; Bowers 2003).

In addition to the wild $B$. oleracea populations, genetic variation in the expression of allelochemicals has been studied extensively in only a few species of wild plants, including both forbs and trees (Fritz et al. 2003; Lawrence et al. 2003; Ode et al. 2004; Zangerl and Berenbaum 2005; Loney et al. 2006). Interpopulation differences in the expression of allelochemicals may be driven by the intensity of selection from herbivores, particularly if natural enemies are scarce or absent (Ode et al. 2004; Zangerl and Berenbaum 2005). Reciprocally, this can have profound effects on plant selection and performance in generalist herbivores, although studies have focused mainly on mammals, such as brush-possums in Australia (O'Reilly-Wapstra et al. 2005; Loney et al. 2006). However, population-related differences in secondary plant chemistry have also been shown to affect the performance of arthropod natural enemies such as parasitoids and predators (Harvey et al. 2005; this study). One of the major shortcomings of existing studies is that detailed information is lacking on the possible factors underlying variation in phenotypic traits such as defense in plants. This should be the focus of future research.

A recent study by Gols et al. (2007) revealed that even under controlled conditions, levels of glucosinolates in shoots of two species of cultivated crucifers changed dramatically over the course of a single growing season. As a result, the development of two insect herbivores and their parasitoids also differed in each of three replicates that were performed (Gols et al. 2007). This suggests that, had further replicates been performed, the effects described here may also have varied temporally in line with changes in plant quality. Nonetheless, under a given set of conditions, we have shown that population-related differences in plant quality can have significant and uniform effects on the development of a herbivore and its parasitoid. Further studies are being planned in which spatial and temporal aspects of interactions involving natural and manipulated populations of $B$. oleracea and its lepidopteran herbivoreparasitoid complexes are investigated. These studies will help to explain factors accounting for the dramatic differences in secondary chemistry among populations of wild cabbage along the south England coast and will shed further light on the relative importance of biotic and abiotic processes shaping direct defense plant strategies in plants.

Acknowledgments The authors thank Leo Koopman and Andre Gidding at Wageningen University, NL, for supplying larvae of Pieris rapae, James Bullock of the Centre for Ecology and Hydrology in Dorset, England, for supplying seeds from wild cabbage populations, Nicole van Dam for interpreting glucosinolate profiles and Wim van der Putten and Roxina Soler for their constructive comments on an earlier version of the manuscript. 


\section{References}

Agrawal, A. A. 2005. Natural selection on common milkweed (Asclepias syriaca) by a community of specialized insect herbivores. Evol. Ecol. Res. 7:651-667.

AKHTAR, Y. and ISMAN, M. B. 2004. Generalization of a habituated feeding deterrent response to unrelated antifeedants following prolonged exposure in a generalist herbivore, Trichoplusia ni. J. Chem. Ecol. 30:1349-1362.

Barbosa, P., Saunders, J. A., Kemper, J., Trumbule, R., Olechnol, J., and Martinat, P. 1986. Plant allelochemicals and insect parasitoids effects of nicotine on Cotesia congregata (Say) (Hymenoptera, Braconidae) and Hyposoter annulipes (Cresson) (Hymenoptera, Ichneumonidae). J. Chem. Ecol. 12:1319-1328.

Barron, M. C., Wratten, S. D., and Barlow, N. D. 2004. Phenology and parasitism of the red admiral butterfly Bassaris gonerilla (Lepidoptera : Nymphalidae). N.Z. J. Ecol. 28:105-111.

Benrey, B., Callejas, A., Rios, L., Oyama, K., and Denno, R. F. 1998. The effects of domestication of Brassica and Phaseolus on the interaction between phytophagous insects and parasitoids. Biol. Cont. 11:130-140.

Bowers, M. D. 2003. Hostplant suitability and defensive chemistry of the Catalpa sphinx, Ceratomia catalpae. J. Chem. Ecol. 29:2359-2367.

Buskov, S., Serra, B., Rosa, E., Sorensen, H., and Sorensen, J. C. 2002. Effects of intact glucosinolates and products produced from glucosinolates in myrosinase-catalyzed hydrolysis on the potato cyst nematode (Globodera rostochiensis cv. Woll). J. Ag. Food Chem. 50:690-695.

CAMPBell, B. C. and DufFEY, S. S. 1979. Tomatine and parasitic wasps-potential incompatibility of plant antibiosis with biological control. Science 205:700-702.

CARTER, M. and FEENY, P. 1999. Host-plant chemistry influences oviposition choice of the spicebush swallowtail butterfly. J. Chem. Ecol. 25:1999-2009.

Charnov, E. L. 1982. The Theory of Sex Allocation. Princeton University Press, Princeton, New Jersey.

Duffey, S. S., Bloem, K. A., and CAmpbell, B. C. 1986. Consequences of sequestration of plant natural products in plant-insect-parasitoid interactions, pp. 31-60, in D. J. Boethel and D. Eikenberry (eds.). Interactions of Plant Resistance and Parasitoids and Predators of Insects. Horwood Press, Chichester, UK.

Fahey, J. W., Zalcmann, A. T., and Talalay, P. 2002. The chemical diversity and distribution of glucosinolates and isothiocyanates among plants. Phytochemistry 59:237-237.

Fox, L. R. 1981. Defense and dynamics in plant-herbivore systems. Am. Zool. 21:853-864.

Fritz, R. S., Hochwender, C. G., Brunsfeld, S. J., and Roche, B. M. 2003. Genetic architecture of susceptibility to herbivores in hybrid willows. J. Evol. Biol. 16:1115-1126.

Giamoustaris, A. and Mithen, R. 1995. The effect of modifying the glucosinolate content of leaves of oilseed rape (Brassica napus ssp. oleifera) on its interaction with specialist and generalist pests. Ann. Appl. Biol. 126:347-363.

Gols, R., RaAijmakers, C. E., Van Dam, N. M., Dicke, M., Bukovinszky, T., and Harvey, J. A. 2007. Temporal changes affect plant chemistry and tritrophic interactions. Basic Appl. Ecol (in press). DOI 10.1016/j.baae.2006.09.005

Gunasena, G. H., Vinson, S. B., and WiLliams, H. J. 1990. Effects of nicotine on growth, development, and survival of the tobacco budworm (Lepidoptera, Noctuidae) and the parasitoid Campoletis sonorensis (Hymenoptera, Ichneumonidae). J. Econ. Entomol. 83:1777-1782.

HARVEY, J. A. 2005. Factors affecting the evolution of development strategies in parasitoid wasps: the importance of functional constraints and incorporating complexity. Entomol. Exp. Appl. 117:1-13.

HARVEY, J. A., VAN DAM, N. M., and GoLS, R. 2003. Interactions over four trophic levels: foodplant quality affects development of a hyperparasitoid as mediated through a herbivore and its primary parasitoid. J. Anim. Ecol. 72:520-531.

Harvey, J. A., VAn NouHuYs, S. and BIERE, A. 2005. Effects of quantitative variation in allelochemicals in Plantago lanceolata on development of a generalist and a specialist herbivore and their endoparasitoids. J. Chem. Ecol. 31:287-302.

Harvey, J. A., Van Dam, N. M., Witjes, L. M. A., Soler, R., and Gols, R. 2007. Effects of dietary nicotine on the development of an insect herbivore, its parasitoid and secondary hyperparasitoid over four trophic levels. Ecol. Entomol. 32:15-23.

HaVILL, N. P. and RafFA, K. F. 2000. Compound effects of induced plant responses on insect herbivores and parasitoids: implications for tritrophic interactions. Ecol. Entomol. 25:171-179.

HunTER, A. F. 2000. Gregariousness and repellent defences in the survival of phytophagous insects. Oikos 91:213-224 
Irwin, R. E., Strauss, S. Y., Storz, S., Emerson, A., and Guibert, G. 2003. The role of herbivores in the maintenance of a flower color polymorphism in wild radish. Ecology 84:1733-1743.

KARBAN, R. and BALDWIN, I. T. 1997. Induced Responses to Herbivory. University of Chicago Press, Chicago.

Lawrence, R., Potts, B. M., and Whitham, T. G. 2003. Relative importance of plant ontogeny, host genetic variation and leaf age for a common herbivore. Ecology 85:1171-1178.

LEE, J. C. and HEIMPEL, G. E. 2005. Impact of flowering buckwheat on Lepidopteran cabbage pests and their parasitoids at two spatial scales. Biol. Control 34:290-301.

Lei, G. C., Vikberg, V., Niemenen, M., and KuUssaAri, M. 1997. The parasitoid complex attacking Finnish populations of the Glanville fritillary Melitaea cinxia (Lep: Nymphalidae), an endangered butterfly. J. Nat. Hist. 31:635-648.

Li, Q., Eigenbrode, S. D., Stringham, G. R., and Thiagarajah, M. R. 2000. Feeding and growth of Plutella xylostella and Spodoptera eridania on Brassica juncea with varying glucosinolate concentrations and myrosinase activities. J. Chem. Ecol. 26:2401-2419.

Loney, P. E., Mcarthur, C., PotTs, B. M., and Jordan, G. J. 2006. How does ontogeny in a Eucaplyptus species affect patterns of herbivory by brushtail possums? Funct. Ecol. 20:982-988.

Mithen, R. F. 2001. Glucosinolates and their degradation products. Adv. Bot. Res. 35:213-262.

Mithen, R., Raybould, A. F., and Giamoustaris, A. 1995. Divergent selection for secondary metabolites between wild populations of Brassica oleracea and its implications for plant-herbivore interactions. Heredity 75:472-484.

Moyes, C. L., Collin, H. A., Britton, G., and Raybould A. F. 2000. Glucosinolates and differential herbivory in wild populations of Brassica oleracea. J. Chem. Ecol. 26:2625-2641.

Muller, C. and Riederer, M. 2005. Plant surface properties in chemical ecology. J. Chem. Ecol. 31:2621-2651.

Muller, C., Agerbirk, N., Olsen, C. E., Boeve, J-L., Schaffner, U., and Brakefield, P. M. 2001. Sequestration of host plant glucosinolates in the defensive hemolymph of the sawfly Athalia rosae. J. Chem. Ecol. 27:2505-2516.

ODE, P. J. 2006. Plant chemistry and natural enemy fitness: Effects on herbivore and natural enemy interactions. Annu. Rev. Entomol. 51:163-185.

Ode, P. J., Berenbaum, M. R., Zangerl, A. R., and Hardy, I. C. W. 2004. Host plant, host plant chemistry and the polyembryonic parasitoid Copidosoma sosares: indirect effects in a tritrophic interaction. Oikos 104:388-400.

O'Reilly-Wapstra, J., Potts, B., Mcarthur, C., Davies, N., and Tilyard, P. 2005. Inheritance of resistance to mammalian herbivores and of plant defensive chemistry in an Eucalyptus species. J. Chem. Ecol. 31:357-375.

ORR, D. B. and BoETHEL, D. J. 1986. Influence of plant antibiosis through four trophic levels. Oecologia 70:242-249.

Piepho, H. P., Buchse, A., and Emrich, K. 2003. A hitchhiker's guide to mixed models for randomized experiments. J. Agron. Crop Sci. 189:310-322.

Potter, M. J., Vanstone, V. A., Davies, K. A., Kirkegaard, J. A., and Rathjen, A. J. 1999. Reduced susceptibility of Brassica napus to Pratylenchus neglectus in plants with elevated root levels of 2phenylethyl glucosinolate. J. Nematol. 31:291-298.

Price, P. W., Bouton, C. E., Gross, P., Mcpheron, B. A., Thompson, J. N., and Weis, A. E. 1980. Interactions among three trophic levels: influence of plants on interactions between insect herbivores and natural enemies. Annu. Rev. Ecol. Syst. 11:41-65.

Ratzka, A., Vogel, H., Kliebenstein, D. J., Mitchell-Olds, T., and Kroymann, J. 2002. Disarming the mustard oil bomb. Proc. Natl. Acad. Sci. USA 99:11223-11228.

RENWICK, J. A. and LOPEZ, A. K. 1999. Experience-based food consumption by larvae of Pieris rapae: addiction to glucosinolates? Entomol. Exp. Appl. 91:51-58.

RostÁs, M., Bennett, R., and Hilker, M. 2002. Comparative physiological responses in Chinese cabbage induced by herbivory and fungal infection. J. Chem. Ecol. 28:2449-2463.

SLANSKY, F. and FEENY, P. 1977. Stabilization of the rate of nitrogen accumulation by larvae of the cabbage butterfly on wild and cultivated food plants. Ecol. Monogr. 47:209-228.

Soler, R., Bezemer, T. M., Van Der Putten, W. H., Vet, L. E. M., and Harvey, J. A. 2005. Root herbivore effects on aboveground herbivore, parasitoid and hyperparasitoid performance via changes in plant quality. J. Anim. Ecol. 74:1121-1130.

TraugotT, M. S. and Stamp, N. E. 1996. Effects of chlorogenic acid-and tomatine-fed caterpillars on performance of an insect predator. Oecologia 109:265-272.

VAN DAM, N. M. and HARE, J. D. 1998. Biological activity of Datura wrightii glandular trichome exudate against Manduca sexta larvae. J. Chem. Ecol. 24:1529-1549. 
VAN DAM, N. M., HADWICH, K., and BALDWIN, I. T. 2000. Induced responses in Nicotiana attenuata affect behavior and growth of the specialist herbivore Manduca sexta. Oecologia 122:371-379.

VAN DAM, N. M., WITJES, L., and SvATOS, A. 2004. Interactions between aboveground and belowground induction of glucosinolates in two wild Brassica species. New Phytol. 161:801-810.

VAn Loon, J. J. A. and Schoonhoven, L. M. 1999. Specialist deterrent chemoreceptors enable Pieris caterpillars to discriminate between chemically different deterrents. Entomol. Exp. Appl. 91:29-35.

Wittstock, U., Agerbirk, N., Stauber, E. J., Olsen, C. E., Hippler, M., Mitchell-Olds, T., Gershenzon, J., and Vogel, H. 2004. Successful herbivore attack due to metabolic diversion of a plant chemical defense. Proc. Natl. Acad. Sci. USA 101:4859-4864.

Wold, E. N. and MARQuis, R. J. 1997. Induced defense in white oak: Effects on herbivores and consequences for the plant. Ecology 78:1356-1369.

Wold-Burkness, S. J., Hutchinson, W. D., Lee, J. C., Hines, R. L., Bolin, P. C., and Heimpel, G. E. 2005. A long-term survey of parasitoid species composition and parasitism of Trichoplusia ni (Lepidoptera : Noctuidae), Plutella xylostella (Lepidoptera : Plutellidae), and Pieris rapae (Lepidoptera : Pieridae) in Minnesota cabbage. J. Entomol. Sci. 40:211-221.

ZANGERL, A. R. and BERENBAUM, M. R. 2005. Increase in toxicity of an invasive weed after reassociation with its coevolved herbivore. Proc. Nat. Acad. Sci. USA 102:15529-15532. 